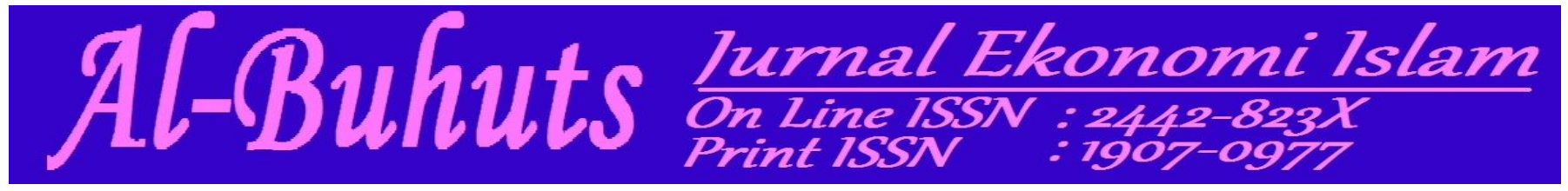

Volume. 15, Nomor 1, Juni 2019

\title{
Persentuhan Filantropi Islam dan Budaya Lokal
}

(Studi Terhadap Tradisi Pogogutat Suku Mongondow di Sulawesi Utara)

\author{
Muhibbuddin
}

IAIN Sultan Amai Gorontalo

muhibiain75@gmail.com

\begin{abstract}
Abstrak
Pogogutat culture in the Mongondow tribe in North Sulawesi is one of the local wisdoms in Indonesia which is loaded with various meanings. This cultural presence is in contact with community activities whose purpose is to improve the quality of life of the people. Practically, the tradition of pogogutat is carried out simultaneously by the community if there is one person holding a celebration in the form of providing assistance in the form of material, energy and thoughts. Pogogutat culture among the Mongondow people can be understood among others as a form of an identity as a Muslim community that has the character of ta'awun (please help), helping each other in order to spread the symbols of Islam as part of religious advice. This tradition has a close relationship with the concept of Islamic philanthropy in this case can be interpreted as a movement, both carried out by individuals and groups with the aim of improving the quality of life of society through a "culture of giving".
\end{abstract}

Keyword : Islamic Philippines, Local Culture

\section{A. Latar Belakang}

Relasi Islam dan budaya lokal telah menjadi isu yang menarik perhatian masyarakat khususnya akademisi. Fenomena keberagamaan atau keislaman yang muncul di Indonesia sangat rentan dengan sentuhan budaya lokal yang berkembang jauh sebelum Islam masuk ke-Nusantara. Persoalan agama dan budaya terus menjadi diskursus hangat untuk dikaji dan diteliti. Sebagian kelompok berpendapat bahwa agama harus terpisah dari budaya, karena agama bukan menjadi unsur 
penting dalam tatanan sosial masyarakat. ${ }^{1}$ Di sisi lain muncul pendapat bahwa agama dan budaya tidak dapat dipisahkan. Agama dan budaya memiliki hubungan timbal- balik dengan tetap memperhatikan dan menjaga hal-hal yang berkaitan dengan kemurnian agama.

Perseteruan agama dan budaya kemudian memunculkan polemik, apakah budaya yang telah hidup dan berkembang di masyarakat harus tunduk kepada hukum agama, atau agama yang harus beradaptasi terhadap budaya yang hidup dan berkembang di masyarakat. Secara umum, ada dua model pendekatan keagamaan dalam studi agama kontemporer, yakni pendekatan tekstual dan kontekstual. Kedua pendekatan ini sering memunculkan pemahaman dan perilaku keagamaan yang berbeda. Pendekatan tekstual lebih membatasi pada sumber nilai al-Quran dan Hadis dengan model pemahaman literalis. Sementara pendekatan kontekstual alQuran dan Hadis tidak terbatas pada teks semata, tetapi terkait dengan konteks sosio-antropologis yang melingkupinya termasuk local wisdom. ${ }^{2}$

Pendekatan keagamaan dalam konteks kearifan lokal salah satunya adalah tradisi pogogutat suku mongondow yang ada di Sulawesi Utara. Tradisi ini tidak mengenal batas sosial karena setiap orang mempunyai ikatan primordial dengan kampung halamannya. Pogogutat merupakan tradisi untuk saling membantu dalam proses pelaksanaan hajatan baik yang berdimensi tahniah (syukuran) maupun takziah (kedukaan).

\footnotetext{
${ }^{1}$ Masyarakat yang memiliki cara pandangan seperti ini dikenal dengan istilah positivisme, yaitu, manusia hanya percaya pada hal yang riil berdasarkan ilmu positif (science positive), observasi, dan eksperimen. Sains dan teknologi dijadikan institusi terakhir dalam mengatasi persoalan tanpa mengikutsertakan dimensi transendental. Hasan Bakti Nasution, Filsafat Umum (Jakarta: Gaya Media Pratama, 2001), h. 178.

${ }^{2} 5$ M. Amin Abdullah, Studi Agama Normativitas atau Historisitas (Yogyakarta: Pustaka Pelajar, 2011), h. 36
} 
Menelaah lebih dalam makna tradisi pogogutat, di satu sisi menjadi bagian yang begitu penting dalam me-support terlaksananya hajatan keluarga yang berimplikasi pada terjalinnya silaturrahim, sikap berbagi dan menimbulkan kecintaan akan pentingnya saling membantu antar sesama warga masyarakat. Disisi lain kehadiran tradisi ini terus "dipaksa" eksis bertarung dengan derasnya arus modernisme dan praktek hidup hedonis. Kegelisahan ini yang memicu lahirnya tulisan ini untuk mengungkap kearifan lokal yang sudah turun temurun terlaksana pada suku Mongondow yang ada di Sulawesi Utara dan mencoba mempertautkannya dengan konsep filantropi islam.

\section{B. Pembahasan}

Tradisi pogogutat adalah bagian dari wujud kerjasama sosial dalam bentuk interaksi yang terstruktur dalam mengatasi permasalahan pemenuhan kebutuhan dalam merealisasikan hajatan masyarakat di Bolaang Mongondow, Sulawesi Utara. Disamping merupakan bentuk interaksi keagamaan dalam rangka membantu membumikan konsep ta'awun sebagai perintah Allah dan sunah rasul, juga di sisi lain berkorelasi langsung dengan upaya untuk memahami kondisi ekonomi masyarakat setempat. Interaksi sosial keagamaan dengan latar belakang kebutuhan antar individu dan kelompok dalam meringankan beban yang dianggap berat menjadi hal menarik dari kegiatan ini. Tradisi ini masih eksis di tengah masyarakat meskipun di tengah pesatnya terpaan arus globalisasi dan informasi serta gaya hidup yang cenderung hedonis dan individualis.

Sulawesi utara terdiri dari beberapa suku, salah satunya adalah suku Bolaang Mongondow yang sekarang ini sudah terbagi atas lima bagian yakni Bolaang Mongondow utara, Bolaang Mongondow induk, Bolaang Mongondow timur, Bolaang Mongondow selatan dan Kotamobagu yang sekarang ini menjadi 
Votume. 15, Nomor 1, Juni 2019

Halaman. 123-134
Persentwhan Filantropi I slam Dan Budaya Lokal (Studi Terhadap Tradisi Pogogutat Suku Mongondow di Sulawesi Utara)

kotamadya Bolaang Mongondow raya. Mokapog atau Sulawesi utara merupakan negeri yang dikemudian hari berkembang berbagai kerajaan diataranya adalah; Kerajaan Kaidipang, Kerajaan Bintauna, Kerajaan Bolangitang dan Kerajaan Kerajaan lainnya yang berada di Bolaang Mongondow Sulawesi utara. ${ }^{3}$

Bolang Mongondow terdiri dari kata "Bolaang" dan "Mongondow". 4 Bolaang atau golaang berarti : menjadi terang atau terbuka dan tidak gelap karena terlindung oleh pepohonan yang rimbun. Dalam hutan rimba, daun pohon rimbun, sehingga agak gelap. Bial ada bagian yang pohonnya agak renggang, sehingga seberkas sinar matahari dapat menembus kegelapan hutan, itulah yang dimaksud dengan no bolaang atau no golaang. Desa Bolaang terletak di tepi pantai utara Bolaang Mongondow yang pada abad 17 sampa akhir abad 19 menjadi tempat kedudukan istana raja. Bolaang dapat pula berasal dari kata "bolango" atau "balangon" yang berarti laut (ingat: Bolaang uki dan Bolaang itang yang juga terletak di tepi laut). Mongondow dari kata "Momondow" yang berarti : berseru tanda kemenangan. ${ }^{5}$

Dalam kehidupan bermasyarakat dan berkeluarga terdapat falsafah yang memiliki nilai-nilai luhur yang diwariskan oleh para leluhur yaitu "Pogogutat". Pogogutat (persaudaraan) ini sangat nampak dalam hidup keseharian anak negeri mulai dari dari hajatan kecil sampai hajatan besar. Pogogutat inilah secara operasional saling bantu membantu dalam segala aspek kehidupan suka maupun duka. Filosofis ini kemudian di turunkan dalam tiga motto masyarakat Mongondow, yaitu "Mototompia'an" (salin membaiki), "Mototabian" (saling

${ }^{3}$ http://bahrudinpodomi.blogspot.co.id/akses tanggal 10 April 2019

${ }^{4}$ Bernard Ginupit, Tabloid Suara Totabuan Kebudayaan Daerah Bolaang Mongondow, 2006, h. 75

${ }^{5}$ Manus dkk, Bulletin Sejarah pendidikan daerah Sulawesi Utara 1980, h. 15 
menyayangi), “Mototatoban” (saling mengingati). Tradisi Pogogutat di Bolaang Mongondow raya sudah ada sejak masa keemasan kerajaan Kaidipang. ${ }^{6}$

Pogogutat yang diartikan sebagai persaudaraan dan keluarga yang pada awalnya adalah tradisi Momosat ${ }^{7}$ (gotong royong) kerjasama masyarakat Bolaang Mongondow. Sedangkan masyarakat di Bolaang Mongondow utara dan masyarakat Bolaang Mongondow selatan menyebutnya Tradisi Pogogusato. ${ }^{8}$ Meskipun terdapat perbedaan dalam penyebutannya namun tradisi pogogutat di masyarakat bentuknya sama halnya dengan tradisi gotong royong yang saat ini Masyarakat Bolaang Mongondow pada umumnya menyebutnya pogogutat potolu adi. ${ }^{9}$

Bentuk kerjasama Pogogutat/Pogogusato di zaman kerajaan, dikerjakan atas dasar sukarela Masyarakat tanpa mengharap imbalan. Dalam menjalankan tradisi gotong royong, masyarakat Bolaang Mongondow mengerjakannya atas dasar sebagai makhluk sosial. Adapun bentuk tradisi pogogutat di zaman kerajaan yang dulu warga Mongondow menyebutnya tradisi momosat adalah bekerjasama dalam membantu masyarakat yang satu dengan Masyarakat lainnya saat melakukan pembangunan rumah, pembukaan lahan baru sebagai tempat mata pencaharian petani dan bentuk kerjasama lainnya yang membutuhkan tenaga setiap orang. ${ }^{10}$

\footnotetext{
${ }^{6}$ Pitres Sowbowadile, Djeinnie Imbang, Ishak Sandala, Wenny Wuysan, Ali imran Aduka. Kearifan Lokal Kaitannya Dengan Pembentukan Watak Dan Karakter Bangsa Di Kabupaten Bolaang Mongondow Selatan. (Yogyakarta: Kapel Press, 2012), h. 146

${ }^{7}$ Momosat merupakan istilah pertama gotong royong yang ada di bolaang mongondow, momosat adalah sebutan kerjasama masyarakat yang pada hari ini masyarakat mongondow menyebutnya pogogutat. (Salihin Mamonto, Kepala Desa Modayag Kabupaten Bolaang Mongondow Timur, Wawancara, 20 Oktober 2018)

${ }^{8}$ Waris Tanaijo, Kepala Desa Bigo Kabupaten Bolaang Mongondow Utara, Wawancara, 01 Oktober 2018 dan Salihin Mamonto, Kepala Desa Modayag Kabupaten Bolaang Mongondow Timur, Wawancara, 20 Oktober 2018

${ }^{9}$ Potolu adi' asal kata dari tolu adi' (motolu adi') yang berarti ayah, ibu dan anak-anak (tolu = tiga, adi' = anak). Potolu adi' : lebih bersifat kekeluargaan. (Hasan Tanda, Kepala Suku Adat Desa Tanoyan Kabupaten Bolaang Mongondow, Wawancara, 8 November 2018)

${ }^{10}$ Salihin Mamonto, Kepala Desa Modayag Kabupaten Bolaang Mongondow Timur, Wawancara oleh penulis di Modayag, 20 Oktober 2018
} 
Berbeda lain hal dengan tradisi pogogutat di era modern saat ini. dimana tradisi pogogutat diidentikan dengan hajatan yang meliputi perkawinan, khitanan, aqiqah, bai'atan, acara selamatan dan kedukaan. ${ }^{11}$

Pogogutat yang dulunya adalah tradisi momosat adalah salah satu bentuk tradisi kerjasama (gotong royong) yang ada di Bolaang Mongondow raya. meskipun terdapat perbedaan dalam penyebutannya, tradisi momosat sendiri tidak jauh berbeda dengan tradisi pogogutat, hanya saja momosat identik dengan kerjasama yang lebih mengarah kepada bantuan fisik untuk mensukseskan suatu kegiatan, adapun pogogutat lebih identik dengan pemenuhan aspek materi dalam hajatan. Jika tradisi momosat tendensinya mengarah pada jasa tenaga setiap orang, maka tradisi pogogutat terdiri atas keduanya yakni tenaga dan barang.

Tradisi pogogutat di zaman kerajaan hingga saat ini terjadi perubahan bahkan pergeseran nilai di dalamnya. Tradisi pogogutat yang seharusnya tidak mengikat dan dikerjakan atas kesadaran sebagai makhluk sosial sebagai warga masyarakat, masyarakat yang dulunya menjalankan tradisi pogogutat hanya atas dasar kerelaan dan keterpanggilan untuk berempati sesama warga masyarakat yang satu dengan lainnya, tidak ada unsur keterpaksaan dan ketertekanan untuk membalas pemberian orang lain. Masyarakat Mongondow menjadikan pogogutat sebagai ajang pertemuan perkumpulan masyarakat yang meliputi nilai kebersamaan, persatuan, rela berkorban, tolong menolong, dan ajang berbentuk persoalan-persoalan kampung baik yang sifatnya santai atau serius dan dimusyawarakan jalan penyelesaiannya. Kebersamaan yang dimaksud adalah dimana masyarakat Mongondow mau bekerja secara bersama-sama untuk membantu orang lain atau untuk membangun fasilitas yang bisa dimanfaatkan

\footnotetext{
${ }^{11}$ Hasan Tanda, Kepala Suku Adat Desa Tanoyan Kabupaten Bolaang Mongondow, Wawancara oleh penulis 08 November 2018
} 
Votume. 15, Nomor 1, Juni 2019

Halaman. 123-134
Persentwhan Filantropi I slam Dan Budaya Lokal (Studi Terhadap Tradisi Pogogutat Suku Mongondow di Sulawesi Utara)

bersama sehingga tumbuh kebersamaan dalam masyarakat. Kebersamaan yang terjalin dalam gotong royong dapat melahirkan persatuan antar anggota masyarakat sehingga masyarakat menjadi lebih kuat dan mampu menghadapi permasalahan yang muncul. Rela berkorban dan gotong royong membuat masyarakat saling bahu membahu untuk menolong satu sama lain, sekecil apapun kontribusi seseorang dalam gotong royong selalu dapat memberikan pertolongan dan manfaat untuk orang lain. $^{12}$

Secara praktis, tradisi pogogutat dilaksanakan secara serempak oleh masyarakat jika ada salah seorang mengadakan hajatan. Dua dimensi yang akan dilakukan oleh masyarakat yaitu membantu dalam bentuk jasa dan materi. Jasa yang dimaksud adalah turut serta berpartisipasi untuk menghadirkan dan mengadakan segala bahan yang dibutuhkan demi terlenggaranya prosesi acara, misalnya membantu utnuk mengambil bambu, papan, kayu dan prasarana lainnya yang dibutuhkan oleh tuan hajat. Ada juga yang motifnya berupa kesediaan untuk membantu memasak, selama beberapa hari atau keikhlasan sebagai petugas kebersihan. Adapun menyangkut materi berupa kepekaan untuk berbagi dengan mengantarkan bahan makanan pokok sebagai bentuk partisipasi dalam menyukseskan hajatan. Bahan makanan yang menjadi standard hantaran berupa beras, gula dengan takaran yang bervariasi dan biasanya ditambah dengan berbagai varian bahan makanan dan minuman lainnya, tergantung kesanggupan dan keinginan untuk berbagi.

Budaya Pogogutat dikalangan masyarakat Mongondow antara lain dapat dipahami sebagai bentuk dari sebuah identitas sebagai masyarakat muslim yang memiliki karakter ta'awun (tolong menolong), saling membantu dalam rangka

\footnotetext{
${ }^{12}$ Salihin Mamonto, Kepala Desa Modayag Kabupaten Bolaang Mongondow Timur, Wawancara oleh penulis di Modayag, 20 Oktober 2018
} 
menyebarluaskan syiar Islam sebagai bagian dari anjuran agama. Tradisi ini memiliki keterkaitan erat dengan konsep filantropi ${ }^{13}$ Islam dalam hal ini bisa diartikan sebagai gerakan, baik dilakukan oleh individu maupun kelompok dengan tujuan meningkatkan kualitas hidup masyarakat melalui "budaya memberi”.

Definisi filantropi berasal dari Philanthropy: Philos (cinta) dan anthropos (manusia). Lebih jauh lagi konseptualisasi filantropi adalah praktik giving, services, dan association secara sukarela untuk membantu pihak lain. Bahkan bisa dimaknai Voluntary action for the public good atau tindakan sukarela untuk kepentingan publik. Filantropi sendiri hadir dari semangat untuk mendayagunakan dan menumbuhkan kemandirian civil society. Filantropi dalam sejarah kelahirannya sampai dengan sekarang berkembang dalam 2 (dua) varian besar yakni filantropi tradisional dan filantropi keadilan sosial $^{14}$. Hal ini pula di tegaskan oleh Allien Shaw bahwa filantropi bukanlah sekedar karitas, akan tetapi lebih pada pendampingan yang bersifat pemberdayaan berdampak jangka panjang. ${ }^{15}$

Filantropi tradisional beraktifitas dalam ruang karitas, tidak berkelanjutan dan cenderung memaknai filantropi secara an sich. Sedangkan filantropi keadilan sosial menggali secara filosofis bahwa sebenarnya kelahiran nilai-nilai filantropi ini adalah menjawab permasalahan publik yang ada ditengah-tengah masyarakat dengan ciri khas program yang berkelanjutan, bergerak di ranah makro,

\footnotetext{
${ }^{13}$ Kata 'filantropi' (Inggris: philanthropy) merupakan istilah yang tidak dikenal pada masa awal Islam, meskipun belakangan ini sejumlah istilah Arab digunakan sebagai padanannya. Filantropi kadang-kadang disebut al-'ata' al-ijtima'i (pemberian sosial), dan adakalanya dinamakan al-takaful al-insani (solidaritas kemanusiaan) atau 'ata khayri (pemberian untuk kebaikan). Namun, istilah seperti al-birr (perbuatan baik) atau as-sadaqah (sedekah) juga digunakan, lebih lengkap lihat Ibrahim Barbara, (2008), From Charity to Social Change: Trends in Arab Philanthropy Kairo: American University in Cairo Press, h. 92.

${ }^{14}$ Prihatna, A. A. Filantropi dan keadilan sosial. Revitaliasasi Filantropi Islam. (Jakarta: PBB UIN Syarif Hidayatullah dan The Ford Foundation, 2005), hal. 23

${ }^{15}$ Latief, H. Melayani umat: Filantropi Islam dan ideologi kesejahteraan kaum modernis. (Jakarta: PT Gramedia Pustaka Utama, 2010), h. 102
} 
menyelesaikan problem di tingkat struktur dan mengubah sistem. Universalitas konsep filantropi tidak dapat dipungkiri berdampak pada praktik-praktik filantropi yang ada di masyarakat. Begitupun dengan pemahaman filantropi dalam perspektif agama yang kemudian menambah dimensi baru implementasi filantropi keagamaan. Selanjutnya konsep filantropi tidak hanya semata-mata bersinggungan dengan material saja, tetapi juga didefinisikan secara luas konsepsi filantropi yakni memberikan waktu, uang, dan pengetahuan bagaimana cara mengembangkan kebaikan bersama. Artinya keterlibatan secara luas seluruh aktifitas manusia dalam berbagai bidang dengan penuh kerelaan, partisipasi, dedikasi, gagasan, waktu luang, kontribusi materi merupakan bagian yang tidak dapt dipisahkan dari konsepi filantropi. $^{16}$

Filantropi Islam bermakna kedermawanan atau saling memberi pertolongan kepada yang membutuhkan demi menajamkan kepekaan kepada sesama. Awalnya bentuk filantropi ini dilakukan oleh para agamawan sebagai upaya amal kebaikan terhadap sesama. Kenyataan ini dapat dilihat pada doktrin maupun praktik keagamaan di berbagai wilayah sebagai bentuk kesetiakawanan terhadap sesama. Bentuk kedermawanan ini disebut charity yang berarti kecintaan terhadap sesama manusia, dan adakalanya disebut sebagai tindakan sukarela untuk kebaikan umum. $^{17}$

Filantropi Islam yang dimaksudkan adalah kegiatan komunitas yang tujuannya adalah meningkatkan kualitas hidup masyarakat, diantaranya melalui

${ }^{16}$ Ibid.

17 Lihat Mary Ellen and Molly Mead, Effective Philanthropy (London: MIT Press Cambride, 2006), 1. Lihat Helmut K. Anheier and Regina A. List, A Dictionari of Civil Society Philanthropy and The Non- Profit Sector (London: New York: Routledge, 2005), 196. Lihat Thomas D. Watts, "Charity" dalam Encyclopedia of World Poverty, ed M. Odekon (London: Sage Publication, 2006), 1:143. Lihat Robert L. Playton and Michael P. Moody, Understanding Philanthropy (Bloomington and Indianapolis: Indiana University Press, 2008), hal. 6. 
kegiatan memberi. Secara konseptual, filantropi memang agak berbeda dengan tradisi memberi dalam Islam, seperti zakat, infak maupun shadaqah. Filantropi lebih berorientasi pada kecintaan pada manusia dan motivasi moral. Sementara dalam Islam, basis filosofisnya adalah kewajiban dari Allah untuk mewujudkan keadilan sosial di muka bumi. Namun, belakangan istilah-istilah tersebut ini popular dipergunakan secara bersamaan dan bertukaran untuk mengidentifikasi praktik kedermawanan berbasis agama, termasuk di kalangan Muslim. Dalam tulisannya mengenai hal ini, Yusuf Ali mengutarakan bahwa kegiatan amal yang dilakukan selalu memiliki tujuan sosial yang jauh ke depan ${ }^{18}$. Bagi muslim, kegiatan amal bukanlah sekedar berderma dan memberikan sesuatu. Lebih luas dari sekedar memberi, kegiatan amal bagi muslim berarti juga berbagi yang didasari oleh nilai-nilai keimanan kepada apa yang mereka percayai, selain itu juga merupakan bentuk dari doa dan harapan mereka.

Eksistensi agama sebagai fenomena yang kekal abadi, bertalian erat dengan pengaruh realitas sekelilingnya. Praktik-praktik keagamaan pada suatu komunitas masyarakat dikembangkan dari doktrin-doktrin agama, kemudian disesuaikan dengan budaya dan sosio-kultural masyarakat itu sendiri. Pertemuan antara doktrin agama dan realitas budaya, terkadang terlihat secara jelas dalam ritual keagamaan.

Tradisi pogogutat pada masyarakat Mongondow adalah sebagai bukti dari keterpautan antara nilai-nilai agama dan kebudayaan. Pertautan antara doktrin agama dan realitas budaya dimungkinkan terjadi karena agama tidak berada dalam realitas yang vakum. Sikap empati dan kedermawanan sosial yang muatan

\footnotetext{
${ }^{18}$ A. Yusuf Ali .The Holy Qur'an: Text, Translation and Commentary, (Beirut: Dar Alan Early Medieval Scholar', International Journal of Social Economics, 1938), t.th. yang disadur dari Bakar, Irfan Abu., Bamualim, Chaider S. Filantropi Islam dan Keadilan Sosial Studi tentang Potensi, Tradisi dan Pemanfaatan Filantropi Islam di Indonesia. Jakarta: Ford Foundation dan CSRC., 2006., h. 16.
} 
Votume. 15, Nomor 1, Juni 2019

Halaman. 123-134
Persentwhan Filantropi I slam Dan Budaya Lokal (Studi Terhadap Tradisi Pogogutat Suku Mongondow di Sulawesi Utara)

utamanya lahir dari sikap filantorpi Islam terbangun diantaranya melalui pelestarian tradisi ini. Tradisi yang begitu ideal dalam kehidupan bermasyarakat meskipun saat ini nyaris dihempas badai kepunahan atau pergeseran nilai baik bermuara pada konflik internal keluarga, etnik maupun benturan budaya lain. Kekuatan yang masih mengikat terlaksananya tradisi ini adalah kepahaman masyarakat tentang esensi pentingnya meningkatkan sikap empati terhadap kehidupan orang lain.

\section{Penutup}

Tradisi Pogogutat suku Mongondow di Sulawesi Utara adalah satu dari sekian banyak budaya yang masih lestari sampai saat ini. Tradisi ini identik dengan salah satu aspek dari membumikan ekonomi syariah yang berbentuk filantropi Islam. Keinginan untuk berbagi dan menimbulkan kepekaan terhadap sesama adalah misi utama dalam pengembangan ekonomi umat sehingga tidak terjerembab pada sikap hedonisme dan memperkaya diri sendiri. Pemenuhan berbagai keperluan mendasar untuk menyukseskan hajatan warga masyarakat adalah hal yang begitu dinantikan. Warga merasa terpanggil meluangkan waktu untuk berbagi tenaga demi membantu terlaksanakanya hajatan. Demikian pula keinginan untuk membantu dalam bentuk materi berupa pemberian kebutuhan mendasar semampunya merupakan kebiasaan yang sulit dipisahkan dari potret kehidupan pedesaan yang masih kental dengan nuansa kearifan dan kepekaan berbagi.

Pendekatan filantropi kreatif ini semakin mempertegas isu-isu indigenous atau kearifan lokal, hal ini dikarenakan adanya keyakinan bahwa keunikan masyarakat menempatkan posisi individu yang berbeda satu sama lain, begitu juga dengan model pelayanan yang sesuai dengan kebutuhan masyarakat setempat. 
Volume. 15, Nomor 1, Juni 2019

Halaman. 123-134
Persentwhan Filantropi I slam Dan Budaya Lokal (Studi Terhadap Tradisi Pogogutat Suku Mongondow di Sulawesi Utara)

\section{Daftar Pustaka}

Bakar, Irfan Abu., Bamualim, Chaider S. Filantropi Islam dan Keadilan Sosial Studi tentang Potensi, Tradisi dan Pemanfaatan Filantropi Islam di Indonesia. Jakarta: Ford Foundation dan CSRC, 2006.

Bernard Ginupit, Tabloid Suara Totabuan Kebudayaan Daerah Bolaang Mongondow, 2006.

Hasan Bakti Nasution, Filsafat Umum, Jakarta: Gaya Media Pratama, 2011.

Helmut K. Anheier and Regina A. List, A Dictionari of Civil Society Philanthropy and The Non-Profit Sector, London: New York: Routledge, 2005

http://bahrudinpodomi.blogspot.co.id/akses

Latief, H. Melayani umat: Filantropi Islam dan ideologi kesejahteraan kaum modernis. PT Gramedia Pustaka Utama: Jakarta, 2010.

M. Amin Abdullah, Studi Agama Normativitas atau Historisitas ,Yogyakarta: Pustaka Pelajar, 2011

Manus dkk, Bulletin Sejarah pendidikan daerah Sulawesi Utara 1980.

Mary Ellen and Molly Mead, Effective Philanthropy, London: MIT Press Cambride, 2006

Pitres Sowbowadile, Djeinnie Imbang, Ishak Sandala, Wenny Wuysan, Ali imran Aduka. Kearifan Lokal Kaitannya Dengan Pembentukan Watak Dan Karakter Bangsa Di Kabupaten Bolaang Mongondow Selatan. Yogyakarta: Kapel Press, 2012.

Prihatna, A. A. Filantropi dan keadilan sosial. Revitaliasasi Filantropi Islam. (Jakarta: PBB UIN Syarif Hidayatullah dan The Ford Foundation, 2005

Robert L. Playton and Michael P. Moody, Understanding Philanthropy, Bloomington and Indianapolis: Indiana University Press, 2008.

Thomas D. Watts, "Charity" dalam Encyclopedia of World Poverty, ed M. Odekon, London: Sage Publication, 2006. 